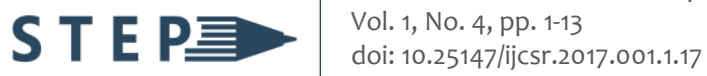

\section{Short Paper \\ The Development of a Wearable Balance Rehabilitation Program Apparatus Using Array Processing Methods for Physical Therapists}

\author{
Arvin Paul D. Bendo \\ Electronics Engineering Department, Adamson University, Manila Philippines \\ bendoarvinpaul@gmail.com \\ Kristoffer James V. Leonen \\ Electronics Engineering Department, Adamson University, Manila Philippines \\ leonenjames15@gmail.com \\ Marjorie S. Mamonong \\ Electronics Engineering Department, Adamson University, Manila Philippines \\ marj.mamonong@gmail.com \\ (corresponding author) \\ Atty. Alfredo U. Ganggangan \\ Electronics Engineering Department, Adamson University, Manila Philippines \\ auganggangan@adamson.edu.ph \\ Anna May A. Ramos, PTRP, MAED \\ Innovation \& Technology Support Office, Adamson University, Manila Philippines \\ anna.may.ramos@adamson.edu.ph
}

Date received: October 8,2017

Date received in revised form: November 14, 2017

Date accepted: February 18, 2018

Recommended citation:

Bendo, A. P. D., Leonen, K. J. V., Mamonong, M. S., Ganggangan, A. U., \& Ramos, A. M. A. (2017). The development of a wearable balance rehabilitation program apparatus using array processing methods for physical therapists. International Journal of Computing Sciences Research, 1(4), 1-13. doi: 10.25147/ijcsr.2017.001.1.17*

*This paper is presented at the 2017 1st International Conference on Redesigning, Re-engineering Academic Direction for Global Competitiveness. 


\begin{abstract}
Purpose - The study aims to develop a single wearable balance rehabilitation program apparatus using array processing methods for physical therapists and for patients with balance disorders. The device which will be attached to the patient's torso in a sitting position on a vestibular ball uses a combination of a 3-axis gyroscopes and 3-axis accelerometers and detects the body fall out threshold angle. It monitors the number of times that the patient will be out of balance during rehabilitation sessions. The device would be capable of sending data to the physical therapist's computer during the patient's rehabilitation session. It will provide the physical therapist a remote for monitoring the progress or regress of the patient's condition. The device will be helpful for the patient's recovery from their balance problem and will reduce possible injuries.
\end{abstract}

Method - The device will be used by a physical therapist during his rehabilitation program in a sitting position on a vestibular ball. The threshold angle set for the device were obtained from conducting tests on what angle the patient could possibly fall on while sitting on the vestibular ball.

Results - Based on the conducted test, the standard acceptable threshold angle is 25.8 degrees. This threshold angle was validated by comparing it to a previous study about sitting balance. Using cross validation technique, the accuracy of the developed balance rehabilitation apparatus was found to be $96.67 \%$.

Conclusion - The device is a single wearable device with multiple sensors attached to the patient's torso and can accurately measure the angles with the use of the combination of 3-axis gyroscopes and accelerometers. It can monitor the shift or tilting of the body of the subject and it prompts the patient when he is about to fall from the ball. Physical Therapists could evaluate the session of the patient from the recorded number of falls.

Recommendations - Future researchers may employ the help of a physical therapist in testing the efficiency, accuracy and reliability of the device. They may ask assistance in establishing the acceptability of the device and its features as it relates to the field of physical therapy. If found feasible and ethically sound, future researchers may ask for the participation of people with balance problems in testing the said device.

Research Implications - The study would be significant and beneficial to physical therapists. It will provide them with an apparatus useful for the implementation of their balance rehabilitation programs. For persons dealing with balance problems, this device will help them correct or improve their stability through numbers of sessions depending on the case of their balance disorder. The device will be helpful for the person's recovery from their balance problem and will reduce the patient's possible injuries.

Keywords - balance, vestibular rehabilitation, accelerometers, gyroscopes, threshold angle articles 


\section{INTRODUCTION}

Having good balance means being able to control and maintain one's body position $\downarrow$ whether one is moving or remaining still. Good balance is important to help a person get around, stay independent, and carry out daily activities. The persons' center of mass is located at the center of the total body mass while the base support is the area of the body in contact with the support surface. Balance disorder is one reason older people fall. The National Institute on Deafness and Other Communication Disorders (NIDCD) states that $4 \%$ (or about 8 million) of American adults report a chronic problem with balance and $1.1 \%$ (or about 2.4 million American adults) were reported as having a chronic problem with dizziness alone (NIDCD, 2010). In the Philippines, there were 103 cases of vertigo out of 3056 new patients seen in 2002. The Department of Family Medicine in Philippine General Hospital reported that out of 20, 902 new patients consulted, there were 528 new reports of dizziness and vertigo. In a report in the outpatient department of the University of Sto. Tomas, Magiba-Caro, Chiong and Jose (2003) reported that there were 688 patients who sought medical attention to relieve dizziness.

A balance disorder is a condition that makes one feel unsteady or dizzy. If one were standing, sitting, or lying down, an individual might feel as though he/she is moving, spinning, or floating (NIDCD, 2014). If an individual were walking, one might suddenly feel as though he/she is tipping over. To have a normal balance, many body systems must function appropriately. When these systems are not functioning well, one can experience balance problems. Balance disorder greatly affects a person's quality of life (Salzman, 2010). It limits the affected individual from many activities that a normal person can normally do effortlessly.

There are many ways to treat balance disorders. Treatments vary depending on the cause. Therapists provide balance rehabilitation program that involves customized exercises to develop strength and balance skills. The balance rehabilitation therapy reduces falls and improves patient's balance.

Loss of Balance and Fall Detection System (patent number US20090076419A1) is a wearable monitoring device which determines the patient's activity, loss of balance, or fall. The patient needs to wear 5 devices for the monitoring - 2 under the sole of their shoes, 2 on their thighs, and 1 on their chest (Namineni \& Jacobus, 2009). With this, the proponents came up with a wearable balance rehabilitation program apparatus for physical therapists using array processing methods. It will be a single wearable device located on the patient's torso with multiple sensors during the patient's session of a balance rehabilitation program in a sitting position on a vestibular ball. The system will alarm the patient when he/she falls out of balance. It will monitor the number of times that the patient will be out of balance in a given time every rehabilitation session depending on the program given by the therapists. The data on the other hand will be used by the therapist. 


\section{OVERVIEW OF THE DESIGN PROJECT}

The general objective of the study is to develop a single wearable balance rehabilitation program apparatus using array processing methods for the use of physical therapists and for the benefit of patients with balance disorders. It commands the patient when he is about to fall from the vestibular ball and evaluates the session of the patient by recording the number of times the patient will fall from the vestibular ball.

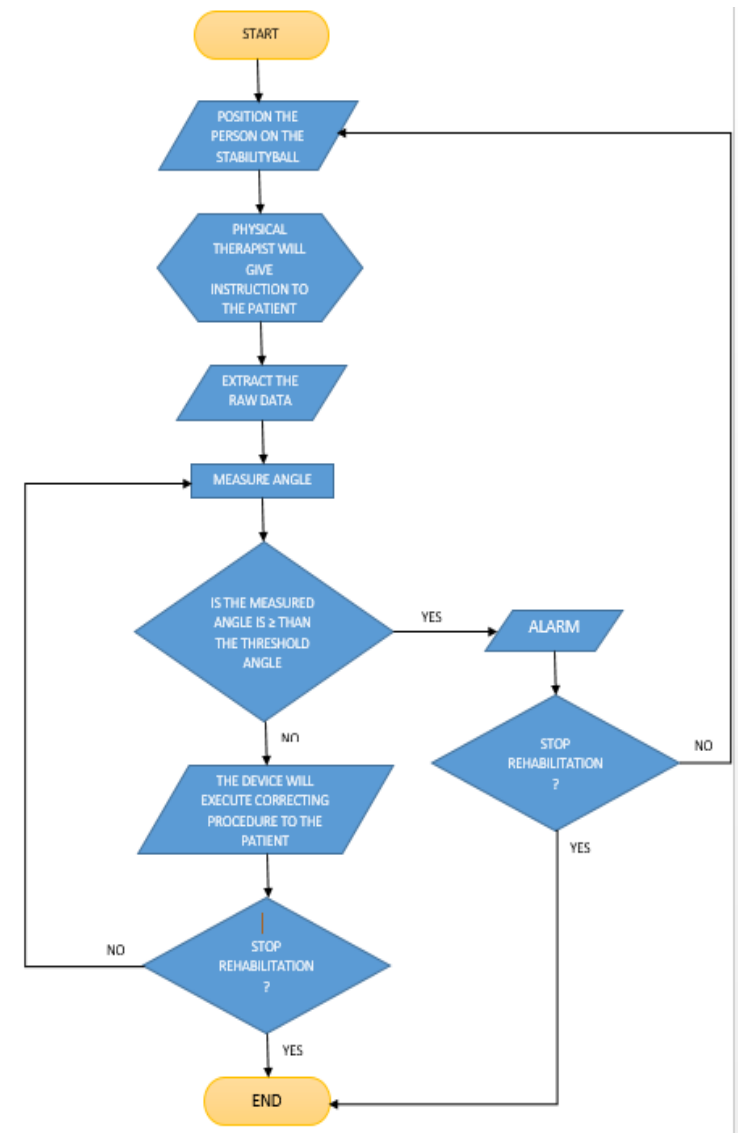

Figure 1. System Diagram

Figure 1 illustrates the operation of the device. It shows how the device will work or function when the device is in use during the exercise program. It shows the step by step functions of the device and how it will comply with the given objectives of the proponents. The process starts with having the patient sit on the vestibular ball. Next, the physical therapist will give instructions to the patient. The sensor will measure the angular displacement. The measurements will then be digitized and will be transmitted to the computer/laptop. If the patient will exceed to the threshold angle, the device will sound an alarm, execute correcting procedures, and then go back to measuring the angular displacement. If the physical therapist stops the rehabilitation, the data will be collected and stored on the physical therapist's personal computer. 


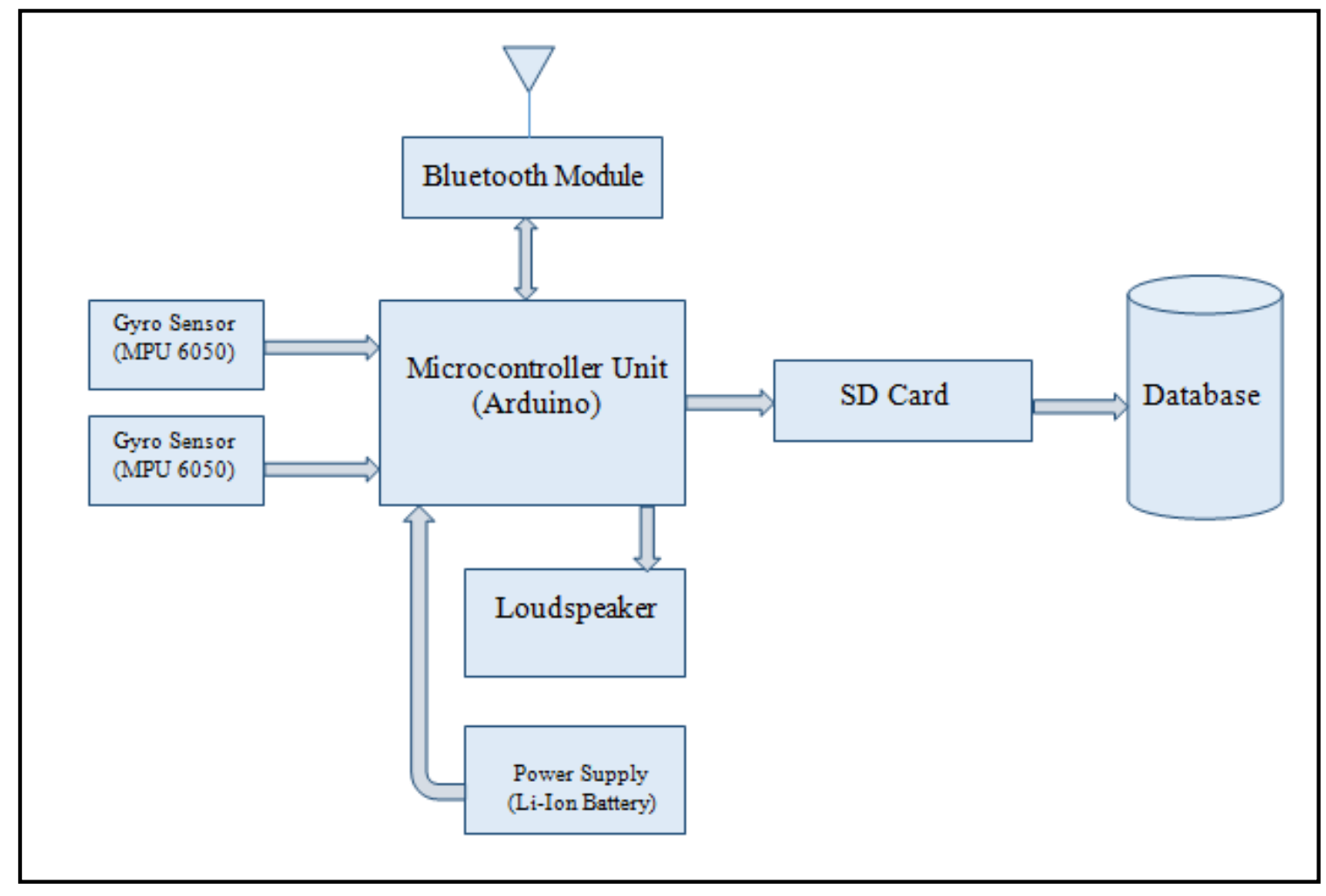

Figure 2. Overall System Design

Figure 2 shows the hardware components and the interconnection of the hardware segments into a functional device. The gyro sensor measures the position angle of the patient sitting on the vestibular ball while the microcontroller unit gathers data and compares it to the threshold values pre-programmed in the system. If the value of the data gathered exceeds the set threshold angle, the microcontroller triggers the alarm to indicate a fall. Also, before reaching the threshold angle, the microcontroller will trigger to output voice commands that correct the position of the body of the patient. The voice commands recorded will be saved to the SD card connected to the microcontroller. The device is controlled by a personal computer via Bluetooth.

As shown in Figure 3, the research is divided into four (4) phases in order to make the devices work: Data Acquisition, Processing, Data Transmission, and the Output.

\section{Data Acquisition}

In using the balance rehabilitation program apparatus, the physical therapists should first assist the patient to attain his 90-degree posture before activating the device. After assisting the patient, the physical therapist could let go of the patient. The gyro sensor MPU-6050 is used to measure the angle of the body during the balance rehabilitation of 
the patient. Gyroscope sensor, particularly MPU-6050 sensor contains a MEMS accelerometer and a MEMS gyro in a single chip that is highly accurate as it contains 16bits analogue to digital conversion hardware for each channel (Arduino, 2017). Threshold angle is set so that when the patient reaches the set threshold angle of the body, the apparatus will sound an alarm to indicate that the patient has fallen.

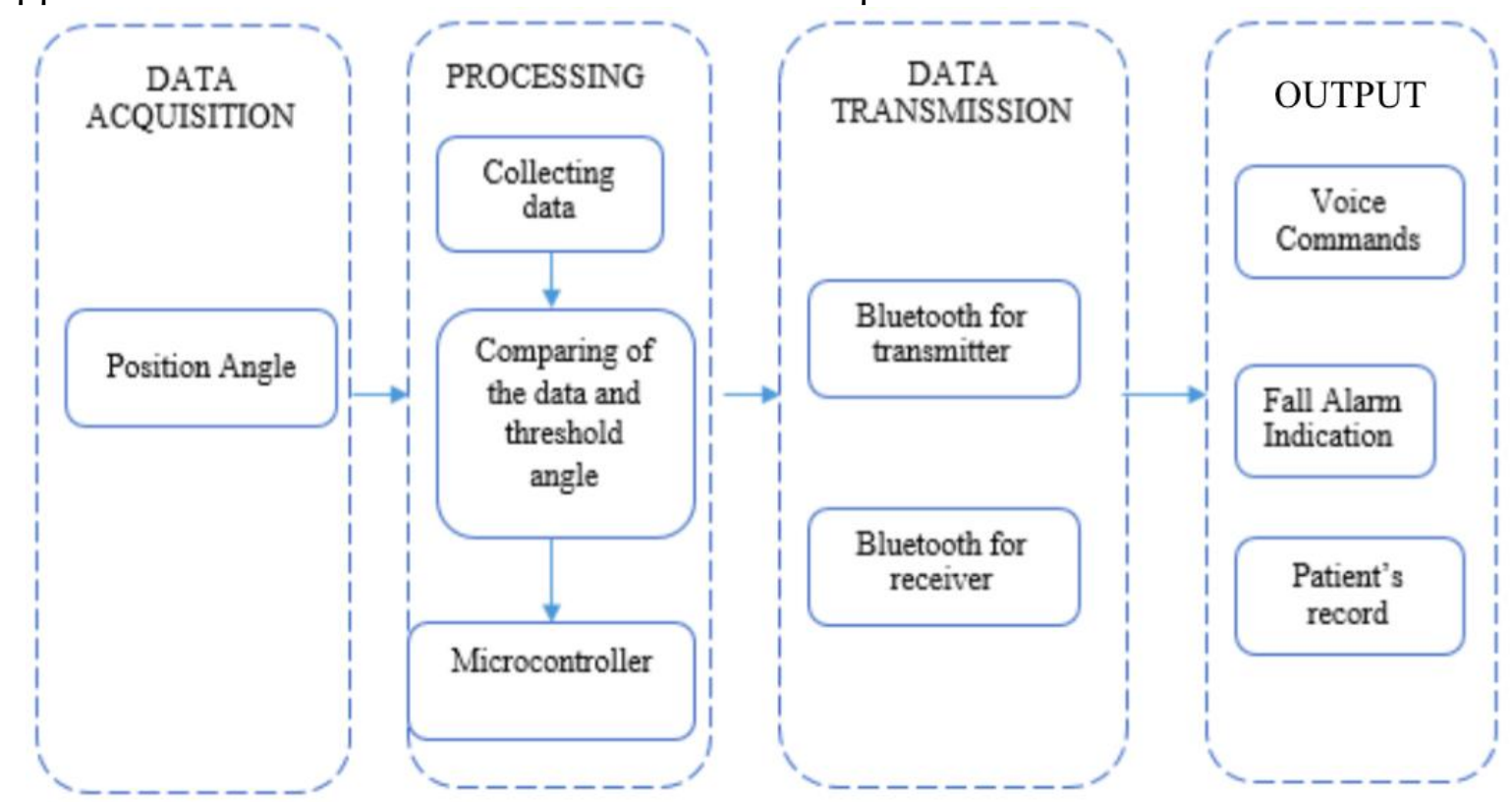

Figure 3. Functional Level

\section{Processing}

The microcontroller collects the data from the sensor. The microcontroller will compare the measured angle reflected on the sensor from the set threshold angle of fall. The proponents used an Arduino board as microcontroller. Arduino boards are capable of reading inputs - light on a sensor, a finger on a button, or a Twitter message - and turn it into an output - activating a motor, turning on an LED, and publishing something online (Arduino, 2017). The threshold angle set was based form the statistics the proponents conducted. The proponents conducted a test on the angle the body fall in a sitting position for backward, forward, rightward, and leftward direction. The average of all the raw data is computed and validated by comparing the data on a study about "Evidence-Based Sitting Balance Examination \& Intervention" that considers 25 degrees as the maximum angle for forward, backward, leftward and rightward position from the center of gravity of the body (Gorman, Harro \& Platko, 2015). When the gathered data reaches the set threshold angle, the microcontroller would trigger the device to alarm and information about the rehabilitation would be sent to the physical therapist's personal computer via Bluetooth.

\section{Data Transmission and Output}


The system would output voice commands when the patient is near the set angle of falling. If a patient is leaning towards right, the system will command the patient to "go left". Also, the system will command the patient to "go right" when the patient is leaning towards left. When the patient is leaning forward, the system will command the patient to "lean backwards". When the patient is leaning backward, the system will command the patient to "lean forward" to be able to go back to its proper posture of maintaining the balance of the body in a sitting position. When the data gathered already exceed the set threshold angle, the system will output an alarm to indicate a fall. All data gathered will be saved to the personal computer of the physical therapist. Data transmission between the device and the physical therapist's personal computer is through Bluetooth. A Bluetooth module is connected to the Arduino board for it to be able to connect wirelessly to the laptop of the physical therapist. It is needed in the device for the important information of the rehabilitation to be automatically recorded and saved on the physical therapist's laptop. A Bluetooth module is a small wireless system designed, manufactured, and certified by the Federal Communications Commission (FCC), Industry Canada (IC), European Conformity or Conformité Européenne (CE), and The European Telecommunications Standards Institute (ETSI). Modules are typically small printed circuit board's (PCB's) that include a Bluetooth processor, as well as all other hardware needed to run the device (Palumbo, 2016).

\section{RESULTS}

The researchers calibrated the device by setting the threshold angle of fall to 25.8 degrees since it is the computed mean for a total of 100 tests of fall in forward, backward, rightward, and leftward direction. The computed threshold correlates to the maximum angle of 25 degrees for the forward, backward, rightward and leftward direction in a study “Don't Just Sit There: Evidence-Based Sitting Balance Examination \& Intervention” conducted last February 2015 (Gorman, Harro \& Platko, 2015).

Table 1. Percentage Difference between the Theoretical and Measured Threshold Angle

\begin{tabular}{|c|c|c|}
\hline Theoretical & Measured & \%Difference \\
\hline 25 & 25.8 & $3.20 \%$ \\
\hline
\end{tabular}

Table 2. Summary of Cross Validation Technique for Accuracy

\begin{tabular}{|c|c|c|}
\hline & Positive & Negative \\
\hline True & 17 & 12 \\
\hline False & 0 & 1 \\
\hline
\end{tabular}

$$
\text { Accuracy }=\frac{T P+T N}{T P+T N+F P+F N} \times 100 \%
$$

Equation 1

For the actual testing, the researchers did 30 trials (See Tables 4-7, Appendix A.). The researchers test the device while a subject is doing the balancing rehabilitation in a 
stability ball. The proponents recorded the angle when the subject already falls out of the vestibular ball and validated when the device responds correctly during the rehabilitation to check the accuracy and reliability of the device. For the accuracy of the device, cross validation technique was used. Table 2 shows the summary of the result of the cross validation technique for the accuracy of the device. For the accuracy of the rehabilitation program apparatus, the formula used was shown in Equation 1.

Using Equation 1, the accuracy of the developed balance rehabilitation apparatus is $96.67 \%$. For the reliability of the developed balance rehabilitation apparatus, the statistical tool Cronbach's alpha was used. For the computation of the reliability, the researchers used the software SPSS.

Table 3. Reliability Statistics

\begin{tabular}{|c|c|c|}
\hline $\begin{array}{c}\text { Cronbach's } \\
\text { Alpha }\end{array}$ & $\begin{array}{c}\text { Cronbach's Alpha Based on } \\
\text { Standardized Items }\end{array}$ & N of Items \\
\hline .924 & .925 & 2 \\
\hline
\end{tabular}

Using the SPSS, the proponents determined the Cronbach's alpha on the data gathered through the series of testing (See Appendix A). They got a 0.924 value of alpha which indicates an excellent value. Therefore, the device's reliability is acceptable.

\section{SUMMARY OF FINDINGS}

Based from the data gathered, the summary of findings of The Development of a Wearable Balance Rehabilitation Program Apparatus Using Array Processing Methods for Physical Therapists as follows:

1. The device is able to give a correction of the body's shift properly;

2. The threshold angle using the analysis of the maximum angle and analysis using statistical approach is approximately around 25 degrees;

3. The device is able to alert or notify the subject when he/she fall out of the ball;

4. The session of the patient can be recorded in a database in Microsoft Access;

5. The device does not restrict the subject's body while maintaining on the ball.

\section{CONCLUSIONS}

Based on the aforementioned findings, the following conclusions are drawn.

1. This device is capable of measuring angle and of detecting the body when it falls out of the threshold angle in a sitting position on a vestibular ball for the rehabilitation program of a physical therapist.

2. The device can accurately measure the angles and monitor it in the data base.

3. This device commands the patient when he is near to falling from the vestibular ball and the physical therapist could evaluate the session of the patient by recording the number of falls. 
4. The device is a single wearable balance device that could help persons with balance disorder.

\section{RECOMMENDATIONS}

The following recommendations are offered as possible ways to improve this study:

1. Employ the help of a physical therapist in testing the efficiency, accuracy and reliability of the device. Request assistance in establishing the acceptability of the device and its features as it relates to the field of physical therapy.

2. If feasible and ethically sound, ask for the participation of people with balance problems when testing the said device.

\section{IMPLICATIONS}

The study may be significant and beneficial to the following:

1. Physical therapists would be provided with an apparatus useful for the implementation of their balance rehabilitation program. The apparatus would help them to monitor their patients' records easier. The device would be capable of sending data to the physical therapist's computer during the patient's rehabilitation session. It would provide the physical therapist a remote in monitoring the progress/regress of a patient condition.

2. For persons dealing with balance problems, this device will help them correct or improve their stability through numbers of sessions depending on the case of their balance disorder. The device will be helpful for a person's recovery from a balance problem and would lessen the possibility of possible injuries for patients who are suffering from balance problems.

Intended clients include people affected with balance problems not necessarily limited to those diagnosed with vertigo or vestibular problems but with anyone suffering from imbalance regardless of cause of imbalance. The device and exercise protocol would be under the recommendation of a physical therapist. The product may also be beneficial for physical therapists that conduct or engage in balance rehabilitation programs.

\section{ACKNOWLEDGEMENT}

Foremost, we would like to dedicate our dissertation to our Almighty God who gave us strength, wisdom and knowledge.

To our parents who unconditionally believed in us and provided us with the help we needed, both morally and financially, to make this project possible, our eternal gratitude.

To our co-authors, Atty. Alfredo U. Ganggangan, PECE and Ms. Anna May A. Ramos, PTRP, MAED, for their valuable guidance and encouragement in completing this research, thank you. 
To the thesis panelists: Engr. Melannie B. Mendoza, Engr. Joan DES. Sta. Ana, Engr. Mark Angelo C. Purio, AAE and Evelyn Q. Raguindin, ASEAN Engr., PECE, for rigidly reviewing our study, our sincere gratitude.

To the faculty of ECE Department and to our beloved Alma Matter Adamson University for preparing us and giving us knowledge and experience, we are forever indebted.

To the Adamson University Center for Research and Development (CRD) and Intellectual Property Development Innovation \& Technology Support Office (ITSO), our sincere gratitude for the trust and support on funding through the development of our dissertation.

Lastly, to our brothers, sisters, and friends, who, in one way or another, helped us in accomplishing this project, thank you.

\section{REFERENCES}

Arduino. (2017). MPU-6050 accelerometer + gyro. Retrieved from http://playground.arduino.cc/Main/MPU-6050.

Arduino. (2017). What is Arduino? Retrieved from https://www.arduino.cc/en/Guide/Introduction

Gorman, F. S. L., Harro, N. C. C., \& Platko, D. C. (2015). Don't just sit there: Evidence-based sitting balance examination \& intervention. Retrieved from http://c.ymcdn.com/sites/www.acutept.org/resource/resmgr/Don\%27t_Just_Sit_The re.pdf

Magiba-Caro, R., Chiong, M., \& Jose, E. (2003). Clinical practice guidelines or peripheral vertigo in adults. Retrieved from http://www.thefilipinodoctor.com/cpm_pdf/ CPM10th\%20VERTIGO.pdf

Namineni, P., \& Jacobus, C. (2009). Loss of balance and fall detection system. U.S. Patent Application No. 12/126,502.

National Institute on Deafness and Other Communication Disorders. (2010). About vestibular disorders. Retrieved from http://vestibular.org/understanding-vestibulardisorder

National Institute on Deafness and Other Communication Disorders. (2014). Balance disorders. Retrieved from https://www.nidcd.nih.gov/health/balance-disorders

Palumbo, M. (2016). What is the difference between Bluetooth module and Bluetooth processor?. Retrieved from https://www.quora.com/What-is-the-differencebetween-bluetooth-module-and-bluetooth-processor

Salzman, B. (2010). Gait and balance disorders in older adults. American Family Physician, $82(1), 61-68$.

Shumway-Cook, A., \& Woollacott, M. (2007). Motor control: Translating research into clinical practice (3rd edition). USA: Lippincott Williams \& Wilkins. 


\section{APPENDIX A: RAW DATA}

Table 4. Raw Data for the measured Threshold Angle

\begin{tabular}{c|c|c|c|c|c|c|c|c|}
\hline & \multicolumn{2}{|c|}{ Forward } & \multicolumn{2}{c|}{ Backward } & \multicolumn{2}{c|}{ Rightward } & \multicolumn{2}{c|}{ Leftward } \\
\hline $\begin{array}{c}\text { Testing } \\
\text { No. }\end{array}$ & $\begin{array}{c}\text { Measured } \\
\text { Angle }\end{array}$ & Threshold & $\begin{array}{c}\text { Measured } \\
\text { Angle }\end{array}$ & Threshold & $\begin{array}{c}\text { Measured } \\
\text { Angle }\end{array}$ & Threshold & $\begin{array}{c}\text { Measured } \\
\text { Angle }\end{array}$ & Threshold \\
\hline 1 & 106 & 16 & 62 & 28 & 62 & 28 & 124 & 34 \\
\hline 2 & 108 & 18 & 69 & 21 & 49 & 41 & 118 & 28 \\
\hline 3 & 108 & 18 & 63 & 27 & 60 & 30 & 119 & 29 \\
\hline 4 & 112 & 22 & 64 & 26 & 59 & 31 & 113 & 23 \\
\hline 5 & 108 & 18 & 64 & 26 & 60 & 30 & 123 & 33 \\
\hline 6 & 114 & 24 & 64 & 26 & 54 & 36 & 121 & 31 \\
\hline 7 & 115 & 25 & 64 & 26 & 65 & 25 & 120 & 30 \\
\hline 8 & 117 & 27 & 64 & 26 & 66 & 24 & 117 & 27 \\
\hline 9 & 108 & 18 & 68 & 22 & 63 & 27 & 120 & 30 \\
\hline 10 & 112 & 22 & 62 & 28 & 64 & 26 & 118 & 28 \\
\hline 11 & 107 & 17 & 69 & 21 & 55 & 35 & 112 & 22 \\
\hline 12 & 111 & 21 & 65 & 25 & 65 & 25 & 119 & 29 \\
\hline 13 & 112 & 22 & 59 & 31 & 63 & 27 & 113 & 23 \\
\hline 14 & 117 & 27 & 68 & 22 & 61 & 29 & 125 & 35 \\
\hline 15 & 109 & 19 & 67 & 23 & 65 & 25 & 109 & 19 \\
\hline 16 & 116 & 26 & 61 & 29 & 68 & 22 & 113 & 23 \\
\hline 17 & 102 & 12 & 67 & 23 & 67 & 23 & 112 & 22 \\
\hline 18 & 114 & 24 & 65 & 25 & 71 & 19 & 115 & 25 \\
\hline 19 & 112 & 22 & 60 & 30 & 55 & 35 & 119 & 29 \\
\hline 20 & 107 & 17 & 64 & 26 & 67 & 23 & 117 & 27 \\
\hline 21 & 121 & 31 & 51 & 39 & 61 & 29 & 115 & 25 \\
\hline 22 & 126 & 36 & 69 & 21 & 68 & 22 & 119 & 29 \\
\hline 23 & 117 & 27 & 72 & 18 & 62 & 28 & 125 & 35 \\
\hline 24 & 116 & 26 & 69 & 21 & 60 & 30 & 120 & 30 \\
\hline 25 & 116 & 26 & 68 & 22 & 63 & 27 & 118 & 28 \\
\hline Mean & & 22.44 & & 25.28 & & 27.88 & & 27.76 \\
\hline Std Dev & & 5.18521 & & 4.228664 & & 4.92601 & & 4.14999 \\
\hline
\end{tabular}


Table 5. Frequency Distribution for Forward and Backward Fall

\begin{tabular}{|l|c|l|c|}
\hline \multicolumn{4}{|c|}{ Frequency Distribution } \\
\hline \multicolumn{2}{|c|}{ Forward } & \multicolumn{2}{c|}{ backward } \\
\hline range & frequency & range & frequency \\
\hline 12 to 16 & 1 & 18 to 21 & 5 \\
\hline 16 to 20 & 8 & 22 to 25 & 7 \\
\hline 21 to 26 & 11 & 26 to 29 & 10 \\
\hline 26 to 30 & 3 & 30 to 33 & 2 \\
\hline 31 to 35 & 1 & 34 to 37 & 0 \\
\hline 36 to 40 & 1 & 38 to 41 & 1 \\
\hline
\end{tabular}

Table 6. Frequency Distribution for Rightward and Leftward Fall

\begin{tabular}{|l|c|l|c|}
\hline \multicolumn{4}{|c|}{ Frequency Distribution } \\
\hline \multicolumn{2}{|c|}{ Right } & \multicolumn{2}{c|}{ Left } \\
\hline range & frequency & range & frequency \\
\hline 19 to 23 & 5 & 19 to 22 & 3 \\
\hline 24 to 28 & 10 & 23 to 26 & 5 \\
\hline 29 to 33 & 6 & 27 to 30 & 12 \\
\hline 34 to 38 & 3 & 31 to 34 & 3 \\
\hline 39 to 43 & 1 & 35 to 38 & 2 \\
\hline
\end{tabular}


Table 7. Cross Validation Technique Table for Accuracy

\begin{tabular}{|c|c|c|c|c|c|c|c|c|c|}
\hline Testing No. & TP & TN & FP & FN & Testing No. & TP & TN & FP & FN \\
\hline 1 & 1 & 0 & 0 & 0 & 16 & 1 & 0 & 0 & 0 \\
\hline 2 & 1 & 0 & 0 & 0 & 17 & 1 & 0 & 0 & 0 \\
\hline 3 & 1 & 0 & 0 & 0 & 18 & 0 & 1 & 0 & 0 \\
\hline 4 & 0 & 1 & 0 & 0 & 19 & 1 & 0 & 0 & 0 \\
\hline 5 & 0 & 1 & 0 & 0 & 20 & 1 & 0 & 0 & 0 \\
\hline 6 & 1 & 0 & 0 & 0 & 21 & 1 & 0 & 0 & 0 \\
\hline 7 & 1 & 0 & 0 & 0 & 22 & 1 & 0 & 0 & 0 \\
\hline 8 & 0 & 1 & 0 & 0 & 23 & 1 & 0 & 0 & 0 \\
\hline 9 & 0 & 1 & 0 & 0 & 24 & 0 & 1 & 0 & 0 \\
\hline 10 & 1 & 0 & 0 & 0 & 25 & 0 & 1 & 0 & 0 \\
\hline 11 & 0 & 1 & 0 & 0 & 26 & 1 & 0 & 0 & 0 \\
\hline 12 & 1 & 0 & 0 & 0 & 27 & 0 & 1 & 0 & 0 \\
\hline 13 & 0 & 1 & 0 & 0 & 28 & 0 & 0 & 0 & 1 \\
\hline 14 & 1 & 0 & 0 & 0 & 29 & 0 & 1 & 0 & 0 \\
\hline 15 & 0 & 1 & 0 & 0 & 30 & 1 & 0 & 0 & 0 \\
\hline
\end{tabular}

